Parkins, R. A., and Bywaters, E. G. L. (1959). Brit. med. J., 1, 536.

Pearse, A. G. E. (1960). Histochemistry, Theoretical and Applied, 2nd ed., p. 284. Churchill, London.

Rosenblatt, M. B. (1933). Amer. J. med. Sci., 186, 558.

Rukavina, J. G., Block, W. D., Jackson, C. E., Falls, H. F., Carey, J. H., and Curtis, A. C. (1956). Medicine (Baltimore), 35, 239.

Schilder, P. (1909). Frankfurt. Z. Path., 3, 782.

Selikoff, I. J., and Robitzeck, E. H. (1947). Amer. J. Path., 23, 1099.

Snapper, I., Turner, L. B., and Moscovitz, H. L. (1953). Multiple Myeloma, p. 88. Grune and Stratton, New York.

Symmers, W. St. C. (1956). J. clin. Path., 9, 187.

Thingstad, R. (1951). Acta med. scand., 140, 1.

Truelove, S. C., Horler, A. R., and Richards, W. C. D. (1955). Brit. med. J., 2, 1590.

Zamcheck, N., and Sidman, R. L. (1953). New Engl. J. Med., 249, 1020 .

\section{HAEMODYNAMIC SHUNTS IN SCHISTOSOMAL COR PULMONALE}

BY

\author{
H. A. ZAKY, M.R.C.P.Ed., T.D.D. \\ Professor
}

A. R. EL-HENEIDY, M.D. Assistant Professor

AND

M. T. FODA, M.D.

Clinical Demonstrator

Department of Chest Diseases, University of Alexandria, Egypt

[With Special Plate]

Schistosomiasis is an endemic disease in Egypt and is associated with a variety of visceral manifestations. The heavy invasion of the portal vein and tributaries by worms and ova leads to hepatosplenomegaly (Fig. A). In advanced cases the schistosome ova may embolize the lungs, lodging in the pulmonary arterioles and producing the picture of cor pulmonale (Zaky, 1952) with characteristic radiological findings (Special Plate, Figs. 1 and 2). This involvement of the portal and pulmonary circulations gives rise to important circulatory changes, and the haemodynamic shunts associated with these are the subject of this paper.

\section{Material and Methods}

Three patients with schistosomal cor pulmonale were studied by the following techniques.

1. Right heart catheterization was performed in the usual manner, but multiple samples of blood were withdrawn from the pre-pulmonary wedge position, midway to the hilum, right or left pulmonary artery, and the main pulmonary artery.

2. Dye-dilution technique, with injection of Evans (azovan) blue dye into the aorta and sampling from the pulmonary artery, to demonstrate an aorto-pulmonary shunt via the bronchial arteries. One cardiac catheter was advanced to the pre-wedge position in the pulmonary artery, while another was introduced into the brachial artery and advanced to the upper part of the descending aorta (Special Plate, Fig. 3). This position was chosen in order to avoid the mouths of the coronary arteries and short-circuiting of the dye through the coronary sinus. It also ensures that the bronchial arteries receive a good quantity of dye, since they arise a short way below the catheter tip. The capacity of each catheter was $2.8 \mathrm{ml}$. One operator injected $10 \mathrm{ml}$ of Evans blue into the arterial catheter as rapidly as passible, but giving a signal at the $3-\mathrm{ml}$. level, at which moment the other operator began to withdraw from the venous catheter for five seconds. This was the first sample, and it averaged $4 \mathrm{ml}$. The syringe was changed and the second sample of $2 \mathrm{ml}$. withdrawn from the blood in the catheter. The first sample represented blood withdrawn from the pulmonary artery during the first $1 \frac{1}{2}$ seconds, and the second sample that withdrawn between $1 \frac{1}{2}$ and 4 seconds. The samples of blood were examined in a Beckman spectrophotometer for the presence of dye.

3. Aortic angiography with a balloon catheter to visualize the bronchial arteries and the pulmonary artery (Special Plate, Fig. 6). A No. 10 cardiac catheter had a rubber balloon fitted over the end hole, and two side holes were made proximal to this. The catheter was advanced via the brachial artery so that the tip lay in the descending aorta just below the lung hilum; $50 \mathrm{ml}$. of $76 \%$ "urografin" (sodium diatrizoate) was injected rapidly, causing the balloon to inflate and block aortic blood-flow, while the remainder of the contrast material escaped from the side holes. Radiographs were taken each second.

\section{Results}

Pulmonary Circulation

The presence of shunts between the bronchial arterial system and the pulmonary artery was suspected on the basis of two sets of observations (Zaky et al., 1959). First, there was an absence of correlation between the size of the pulmonary artery and its luminal pressure. Gross dilatation of the pulmonary artery may be attended with a lower pressure than a smaller enlargement (Special Plate, Figs. 4 and 5). This was inferred to mean an increase in flow rather than in pressure to account for the discrepancy in size. Secondly, a progressive increase in oxygen saturation in the pulmonary artery was found as the catheter proceeded from the

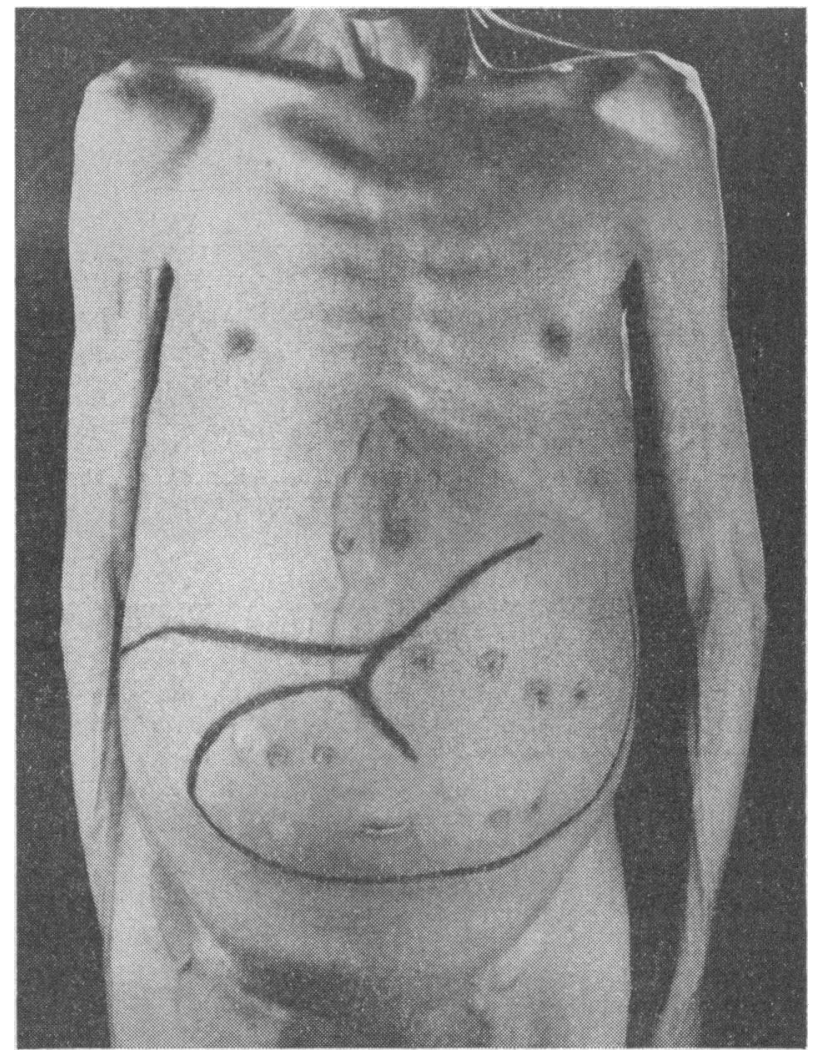

FIG. A.-Patient with schistosomal hepatosplenomegaly. 
proximal trunk to the distal branches, but away from the wedge position (Table I). There was a corresponding diminution in carbon-dioxide content between the trunk and the segmental artery in two cases (Ashba, 1959).

TABle I.-Oxygen Saturation and Carbon-dioxide Content of Blood Samples Obtained at Cardiac Catheterization

\begin{tabular}{|c|c|c|c|c|c|c|c|}
\hline \multirow{2}{*}{$\begin{array}{l}\text { Patient } \\
\text { No. }\end{array}$} & \multicolumn{4}{|c|}{$\begin{array}{c}\text { Oxygen Saturation } \\
(\%)\end{array}$} & \multicolumn{3}{|c|}{$\begin{array}{c}\text { Carbon-dioxide Content } \\
\text { (Vols.\%) }\end{array}$} \\
\hline & $\begin{array}{l}\text { Pulmon- } \\
\text { ary } \\
\text { Trunk }\end{array}$ & $\left\{\begin{array}{l}\text { Pulmon } \\
\text { ary } \\
\text { Artery }\end{array}\right.$ & $\mid \begin{array}{c}\text { Midway } \\
\text { Posi- } \\
\text { tion }\end{array}$ & $\begin{array}{l}\text { Pre- } \\
\text { wedge }\end{array}$ & Artery & $\begin{array}{l}\text { Mixed } \\
\text { Venous }\end{array}$ & $\begin{array}{l}\text { Pre- } \\
\text { wedge }\end{array}$ \\
\hline $\begin{array}{l}1 \\
2 \\
3\end{array}$ & $\begin{array}{l}53 \\
57 \\
58\end{array}$ & $\begin{array}{l}53 \\
57 \\
59\end{array}$ & $\begin{array}{l}55 \\
61 \\
60\end{array}$ & $\begin{array}{l}58 \\
63 \\
66\end{array}$ & $\begin{array}{l}\overline{42 \cdot 3} \\
52 \cdot 1\end{array}$ & $\begin{array}{l}4 \overline{5.4} \\
57.6\end{array}$ & $\begin{array}{l}44 \cdot 7 \\
55 \cdot 3\end{array}$ \\
\hline
\end{tabular}

The pressures found at catheterization in these three patients are shown in Table II.

TABLE II.-Pressures Measured at Cardiac Catheterization at Various Points in the Pulmonary Circulation

\begin{tabular}{c|c|c|c|c|c}
\hline & \multicolumn{5}{|c}{ Mean Pressure (mm. Hg) } \\
\cline { 2 - 6 } $\begin{array}{c}\text { Patient } \\
\text { No. }\end{array}$ & $\begin{array}{c}\text { Pulmonary } \\
\text { Trunk }\end{array}$ & $\begin{array}{c}\text { Pulmonary } \\
\text { Artery }\end{array}$ & $\begin{array}{c}\text { Midway } \\
\text { Position }\end{array}$ & $\begin{array}{c}\text { Pre- } \\
\text { wedge }\end{array}$ & Wedge \\
\hline 1 & 48 & 48 & 45 & 45 & 15 \\
2 & 40 & 40 & 40 & 40 & 11 \\
3 & 49 & 47 & 47 & 47 & 12 \\
\hline
\end{tabular}

\section{Dye-dilution Technique}

The first sample of blood, drawn during the first $1 \frac{1}{2}$ seconds, showed the presence of dye only when examined spectrophotometrically. The second sample, drawn between $1 \frac{1}{2}$ and 4 seconds, showed frank blue discoloration of the centrifuged plasma to the naked eye. This indicates clearly that an appreciable aorto-pulmonary shunt is present.

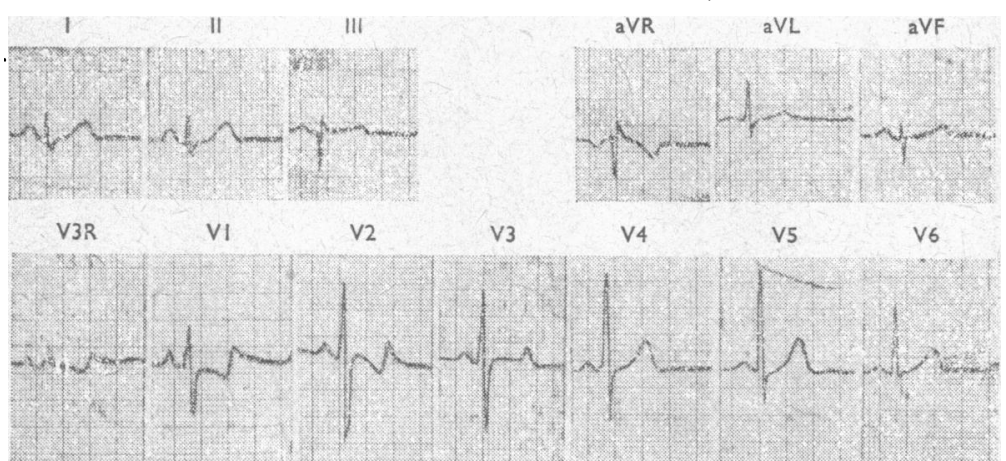

FIG. B.-Electrocardiogram of patient before splenectomy, showing right atrial and right ventricular hypertrophy.

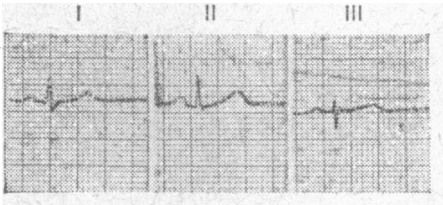

V $3 R$
VI

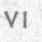

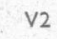

V2

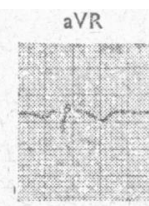

V4
aVL

aVF

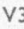

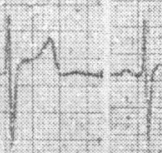

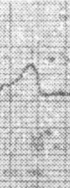

FiG. C.-Electrocardiogram 18 months after splenectomy, showing reduction in height of $\mathrm{P}$ waves and resolution of $\mathrm{T}$-wave inversion in $\mathrm{V} 1$ and $\mathrm{V} 2$.
The intercostal and bronchial arteries are found to fill within one second and the pulmonary artery in two to three seconds (Special Plate, Figs. 6, 7, and 8). The rapid filling of the big branches of the pulmonary artery is direct evidence of the presence of appreciable shunts between the bronchial and pulmonary arteries.

\section{Extrathoracic (Splenic) Shunts}

At cardiac catheterization the oxygen saturation in the inferior vena cava was found in some patients with gross dilatation of the pulmonary artery to be unduly high in relation to that in the superior vena cava. Three of these patients were subjected to splenectomy, and six to 18 months later there was a marked reduction in the size of the heart (Special Plate, Figs. 9 and 10). In addition there was regression in the electrocardiographic evidence of right ventricular hypertrophy and strain (Foda, 1959), as shown in Figs. B and C. Recatheterization showed a normal difference of $4 \%$ in the oxygen saturation between the inferior and superior venae cavae compared to as much as $15 \%$ before splenectomy. The pulmonary arterial pressure in one patient was $80 / 50$ (mean 65 ) $\mathrm{mm}$. $\mathrm{Hg}$ before and $50 / 30$ (mean 40 ) $\mathrm{mm}$. Hg after splenectomy.

Thus extrathoracic shunts across the spleen were postulated to account for a high diastolic loading of the right ventricle, which contributed to the over-all general picture of schistosomal cor pulmonale; this exists in addition to the broncho-pulmonary shunts and the occlusive changes that take place inside the pulmonary circuit itself secondary to the deposition of schistosoma ova. This should give food for thought before deciding on a portacaval shunt operation, because of its probable subsequent haemodynamic implications.

\section{Comment}

As is seen from the above findings, the picture of schistosomal cor pulmonale is a composite one. It incorporates splenic shunts that contribute to diastolic loading of the right ventricle, and bronchopulmonary shunts that increase the systolic work of the right ventricle. Repetitive showers of schistosoma ova that lodge in the branches of the pulmonary artery create further occlusive angiitis which increases the total pulmonary arteriolar resistance. The large size of the pulmonary arteries is therefore due to an increase in flow, pressure, and resistance in competition with each other.

In this respect schistosomiasis, which is a parasitic acquired disease, when complicated by hepatosplenomegaly and cor pulmonale, shows features of the Eisenmenger reaction as described by Wood (1958) in congenital heart disease. This similarity in physiological adaptation is interesting and important. It shows the capacity of the organs to adapt themselves to the organism as a whole, irrespective of the exciting factor which brought the primary changes. 


\section{Summary}

Investigation of haemodynamic changes in schistosomal cor pulmonale showed:

(A) The presence of broncho-pulmonary arterial shunts proved by: (1) absence of correlation between the size of the pulmonary artery and its luminal pressure; (2) a progressive increase in the oxygen saturation in the pulmonary artery along its course ; (3) the appearance in the pulmonary artery in $1 \frac{1}{2}$ seconds of Evans blue dye injected into the aorta ; (4) a sudden increase in the pressure as the catheter was drawn from the wedge to the pre-wedge position; and (5) on aortography by a special technique, the rapid filling of the big branches of the pulmonary artery through the bronchial arteries.

(B) The presence of splenic shunts, as evidenced by: (1) a fall in the oxygen saturation in the inferior vena cava after splenectomy; and (2) a change towards normal in the size of the heart, in the electrocardiogram, and in the pulmunary arterial pressure after splenectomy.

\section{REFERENCES}

Ashba, J. (1959). Thesis, University of Alexandria.

Foda, M. T. (1959). Thesis, University of Alexandria.

Wood, P. (1958), Brit med. J., 2, 701 and 755.

Zaky, H. A. (1952). Dis. Chest, 21, 194.

El-Heneidy, A. R., Tawfick, I. M., Gemei, Y., and Khadr, A. A. (1959). Ibid., 36, 164

\title{
SCHISTOSOMIASIS OF THE CERVIX
}

\author{
BY
}

\author{
ABDEL HAMID BADAWY, M.Ch. \\ Lecturer in Obstetrics and Gynaecology, Kasr el Aini Hospital, Cairo, Egypt
}

Although schistosomiasis usually involves the urinary tract and the rectum, schistosomiasis of the genital tract is not infrequently encountered in areas heavily infested with the disease. The disease may be discovered during examination of patients for other gynaecological conditions or it may itself produce symptoms that will bring the patient for examination. Schistosomiasis may affect any compcnent of the female genital tract, the site of predilection of the infestation differing in different countries according to the infesting species. Thus in countries in which the common species of the worm is Schistosoma mansoni the Fallopian tubes and the ovaries are the organs usually involved (Arean, 1956). In Egypt, where $S$. haematobium is more prevalent, we find that the lower components of the genital tractnamely, the cervix, vagina, and vulva-are the organs more often involved. Moreover, gynaecological manifestations as a whole are more common with the $S$. haematobium than with $S$. mansoni infections.

The importance of schistosomiasis of the cervix is twofold: it may be mistaken for carcinoma and it may possibly, though rarely, predispose to that disease.

The present article is based on cases personally encountered in the years 1950-60 inclusive, together with a study of biopsy material of schistosomiasis of the cervix in the Kasr el Aini Hospital during that period.

Four cases of peculiar interest are reported: in one case carcinoma of the cervix developed on the top of schistosomiasis of the organ; in another a schistosomal papilloma concomitant with pregnancy simulated carcinoma, the pregnancy itself terminating in abortion ; in the third case the disease has caused marked hypertrophy of the cervix; and in the fourth case the presence of schistosomiasis has predisposed to a ureteric fistula after labour.

\section{Material}

During 1950-60 88 cases of schistosomiasis of the female genital tract were seen. The distribution of the lesions among the various components of the genital tract is shown in Table $I$, and the age incidence in Table II.

Schistosomiasis of the vulva was encountered at an earlier age (most of the patients were in the age-groups 11-30 years) than schistosomiasis of the cervix (the majority in the $21-40$ year group). One probable reason is the fact that vulval lesions are noticed by the patients at an earlier age. Nevertheless from this study it is felt that when schistosomiasis of the genital tract affects a woman of over 35 years the cervix is the site of predilection, while if it affects a young girl it occurs in the vulva with greater frequency.

\begin{tabular}{|c|c|c|c|c|c|c|}
\hline \multirow{2}{*}{\multicolumn{2}{|c|}{$\begin{array}{ll}\text { Vulva } & \ldots \\
\text { Vagina } & \ldots \\
\text { Cervix } & \ldots \\
\text { Cervix and vagina } \\
\text { Urethra } \\
\end{array}$}} & $\begin{array}{lrl}\ldots & 9 & \text { cases } \\
\therefore & 25 & , " \\
\cdots & 32 & , " \\
\ldots & 2 & , " \\
\cdots & 2 & , "\end{array}$ & \multicolumn{2}{|c|}{$\begin{array}{l}\text { Corpus uteri .. } \\
\text { Fallopian tube } \\
\text { Ovary ... } \\
\begin{array}{l}\text { Peritoneum and broa } \\
\text { ligament } \quad . .\end{array}\end{array}$} & $\begin{array}{r}\ldots \\
\ddot{\operatorname{ad}} \\
\ldots\end{array}$ & \multirow[t]{2}{*}{$\begin{array}{l}5 \text { cases } \\
7 \quad \text { " } \\
4 \quad " \\
2 \quad \text { ", }\end{array}$} \\
\hline & & \multicolumn{3}{|c|}{ TABLE II } & & \\
\hline Age & & \multicolumn{2}{|c|}{$\begin{array}{l}\text { No. of Cases of } \\
\text { Schistosomiasis of Cervix }\end{array}$} & \multicolumn{3}{|c|}{$\begin{array}{c}\text { No. of Cases of } \\
\text { Schistosomiasis of Vulva }\end{array}$} \\
\hline $\begin{array}{r}0-10 \ldots \\
11-2 ! \\
21-30 \\
31-40 \ldots \\
41-50 \ldots \\
51-60 \ldots\end{array}$ & $\begin{array}{l}\cdots \\
\cdots \\
\cdots \\
\cdots \\
\cdots\end{array}$ & \multicolumn{2}{|l|}{$\begin{array}{r}1 \\
2 \\
14 \\
13 \\
4 \\
0\end{array}$} & \multicolumn{3}{|c|}{$\begin{array}{l}1 \\
5 \\
3 \\
0 \\
0 \\
0\end{array}$} \\
\hline Total & $\ldots$ & \multicolumn{2}{|l|}{34} & \multicolumn{3}{|c|}{9} \\
\hline
\end{tabular}

The macroscopical appearance of the lesion in the 32 cases of cervical schistosomiasis is described in Table III.

TABLE III.-Gross Appearances of Lesion in 32 Cases of
Schistosomiasis of Cervix
Schistosomal papillomata
$\begin{aligned} & \text { Nodular and diffuse hypertrophic cervix } \\ & \text { Erosion of cervix with or without sandy spots }\end{aligned}$
Carcinoma
..

There were three cases of carcinoma of the cervix superimposed on schistosomal affection. All the three were of the squamous-cell type. There was also a case of papillary cystadenocarcinoma superimposed on schistosomiasis of the ovary.

\section{Case 1}

A woman aged 28 was admitted to Kasr el Aini Hospital on May 24, 1959, complaining of offensive yellowish vaginal discharge since her last delivery, four months before admission. She had had four pregnancies; the first three were full-term normal labours and the last was a premature labour of 28 weeks, the child dying four hours after delivery. Menstruation reappeared two months after delivery and had been regular since then, 5/28 days. The last menstrual period ended three days before admission.

On examination her general condition was fair. The chest and heart were free. On vaginal examination the 
FEB. 10, 1962

H. A. ZAKY ET AL.: HAEMODYNAMIC SHUNTS IN SCHISTOSOMAL COR PULMONALE

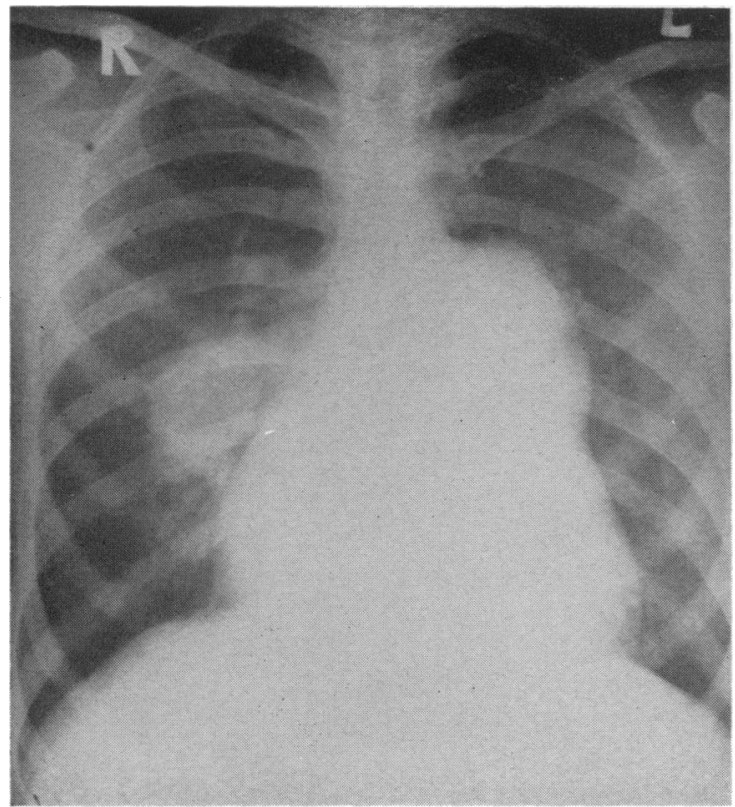

FiG. 1

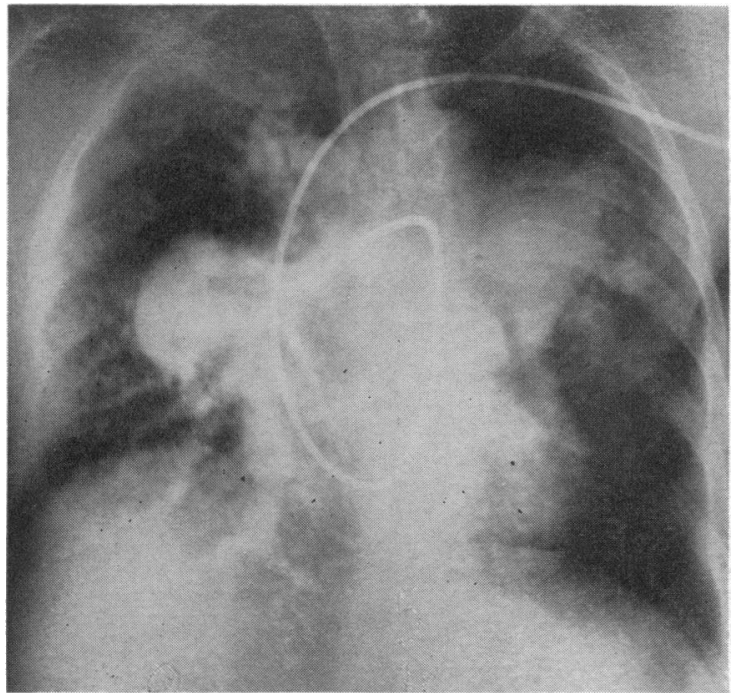

FIG. 2

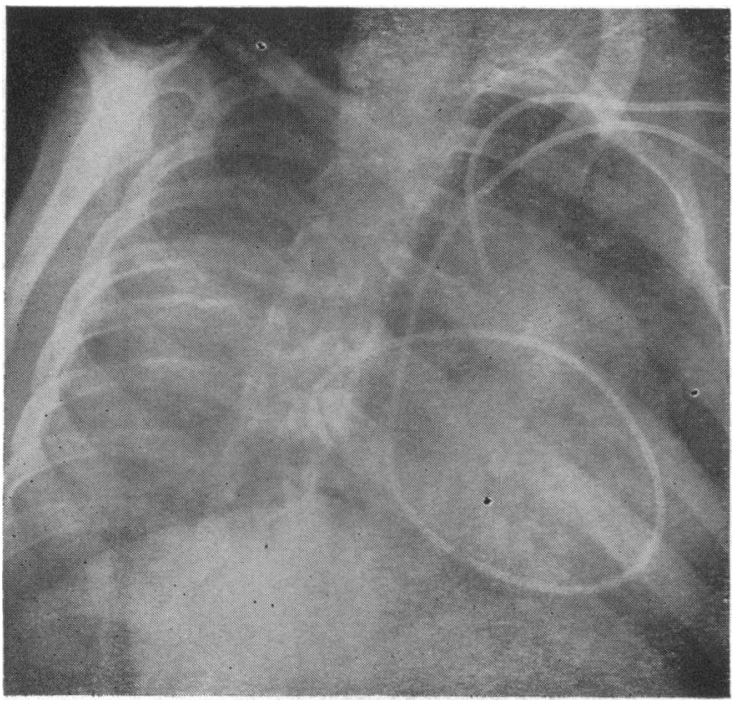

Fia. 3

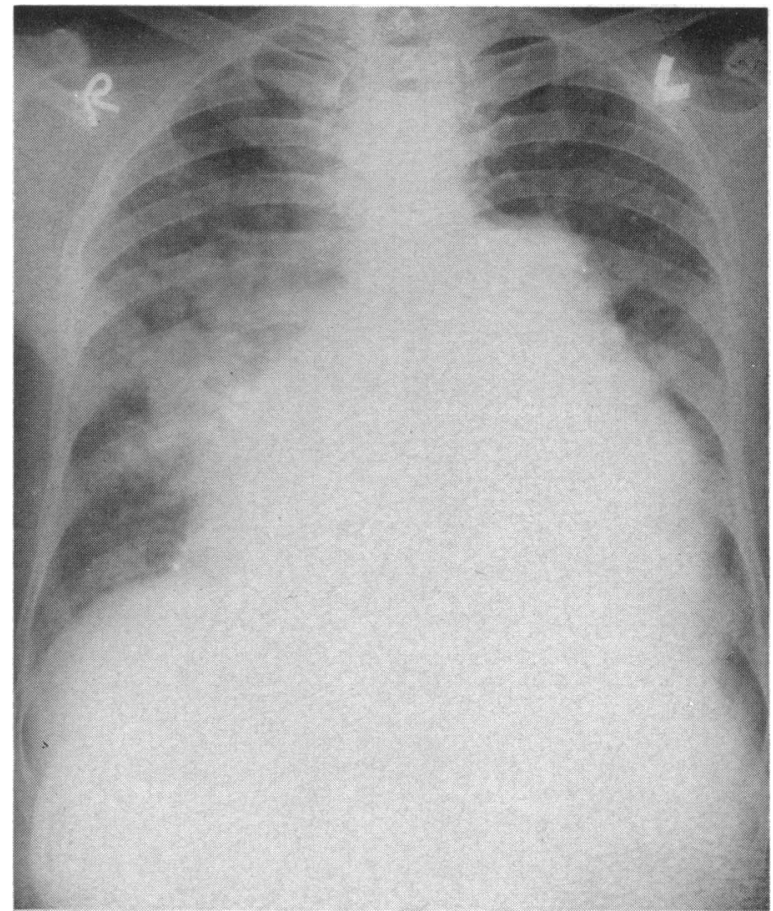

Fig. 4

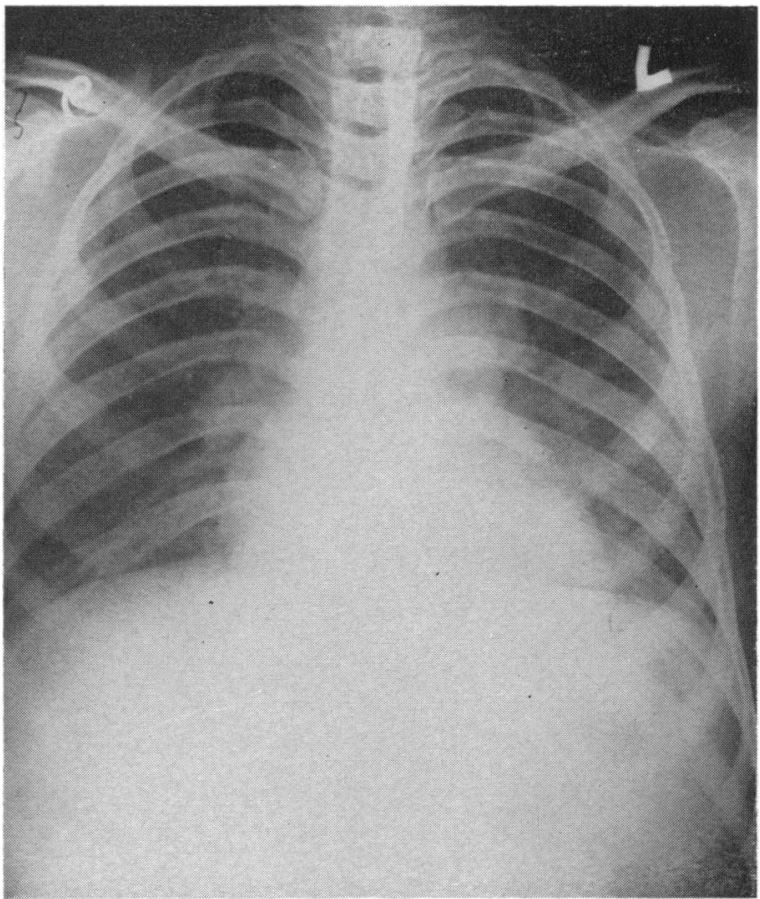

FIG. 5

Fig. 1.-Chest radiograph of patient illustrated in text, showing aneurysmal dilatation of pulmonary arteries.

Fig. 2.-Pulmonary arteriogram of same patient as Fig. 1, demonstrating dilated proximal and distal branches.

FIG. 3.-Right oblique chest radiograph showing cardiac catheters in aorta and pulmonary artery.

FIG. 4.-Right pulmonary artery diameter $5 \mathrm{~cm}$.; mean pulmonary artery pressure $49 \mathrm{~mm} . \mathrm{Hg}$.

Fig. 5.-Right pulmonary artery diameter $2.2 \mathrm{~cm}$.; mean pulmonary artery pressure $54 \mathrm{~mm}$. Hg. Contrast with Fig. 4 . 
H. A. ZAKY ET $A L$.: HAEMODYNAMIC SHUNTS IN SCHISTOSOMAL COR PULMONALE

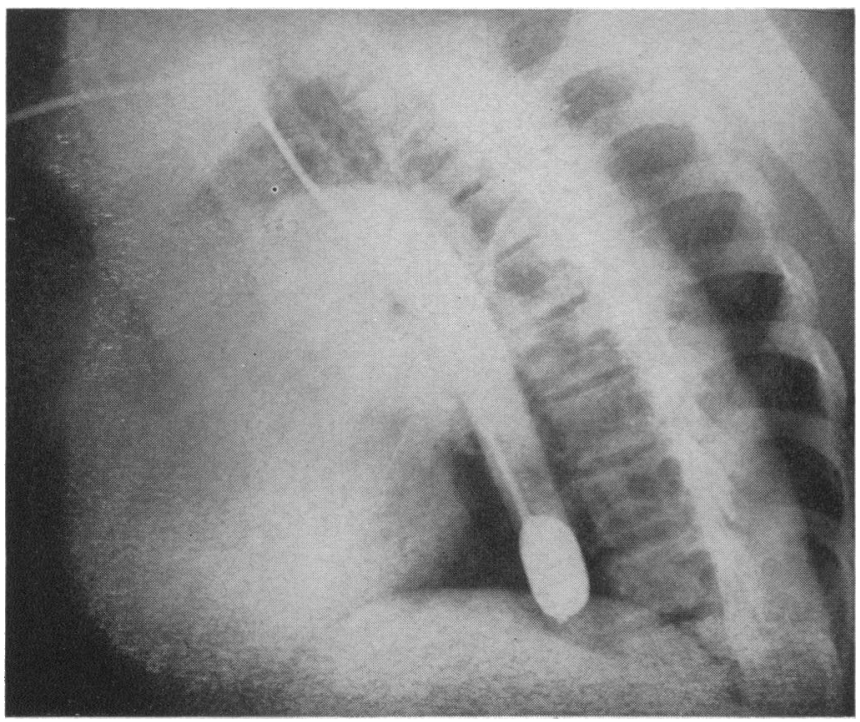

Fig. 6

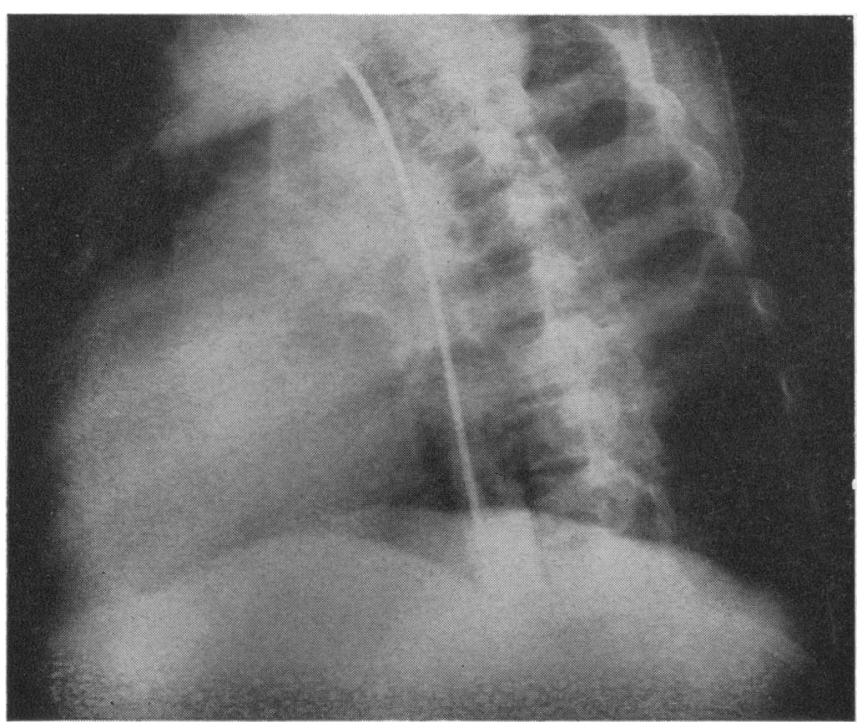

Fic. 7

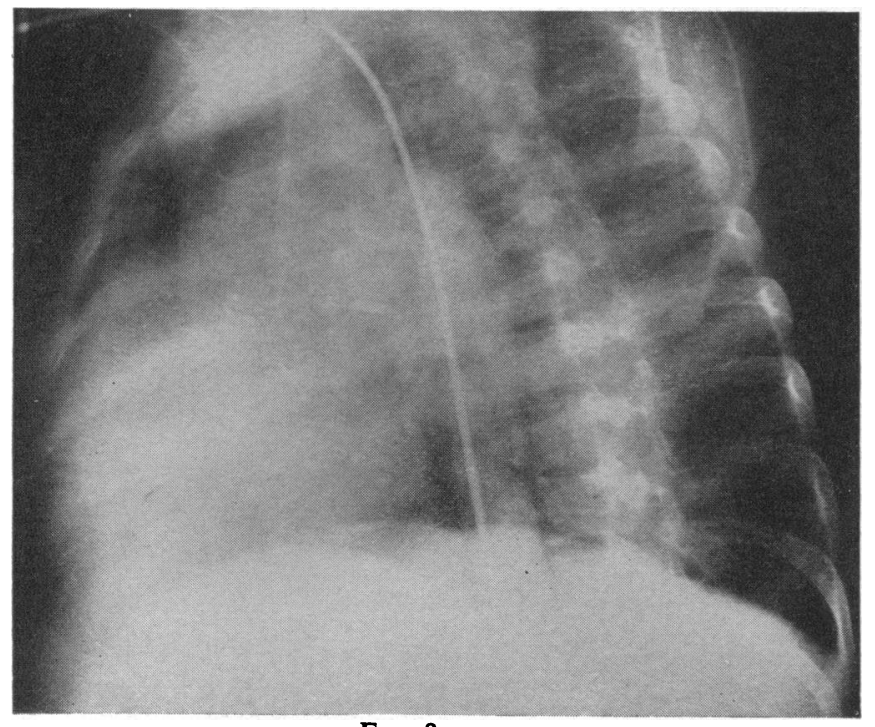

Fig. 8

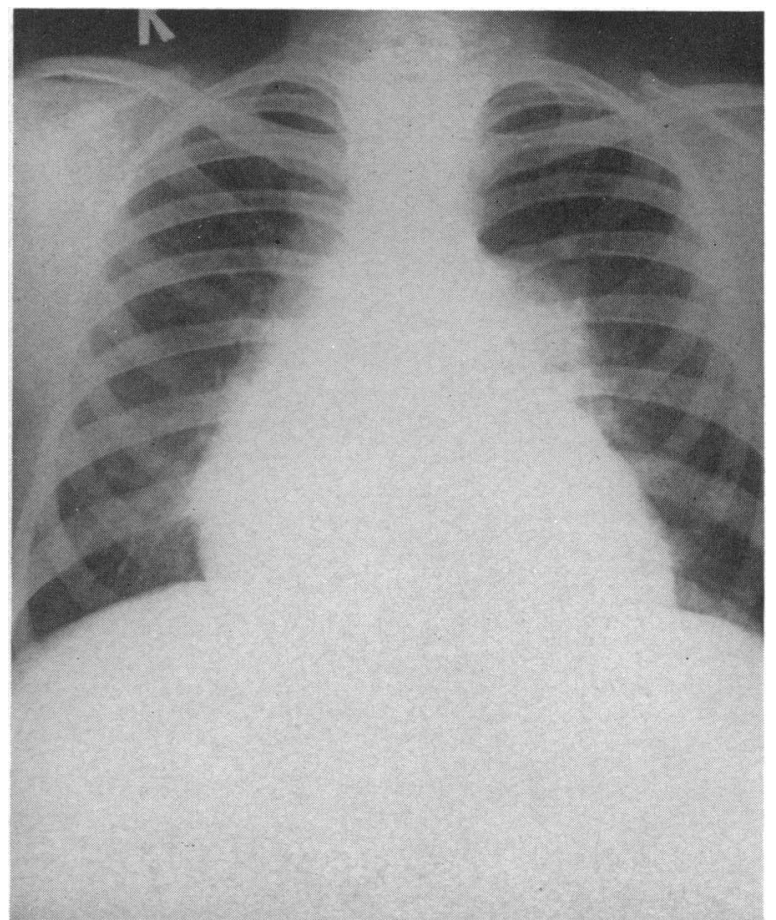

Fig. 9

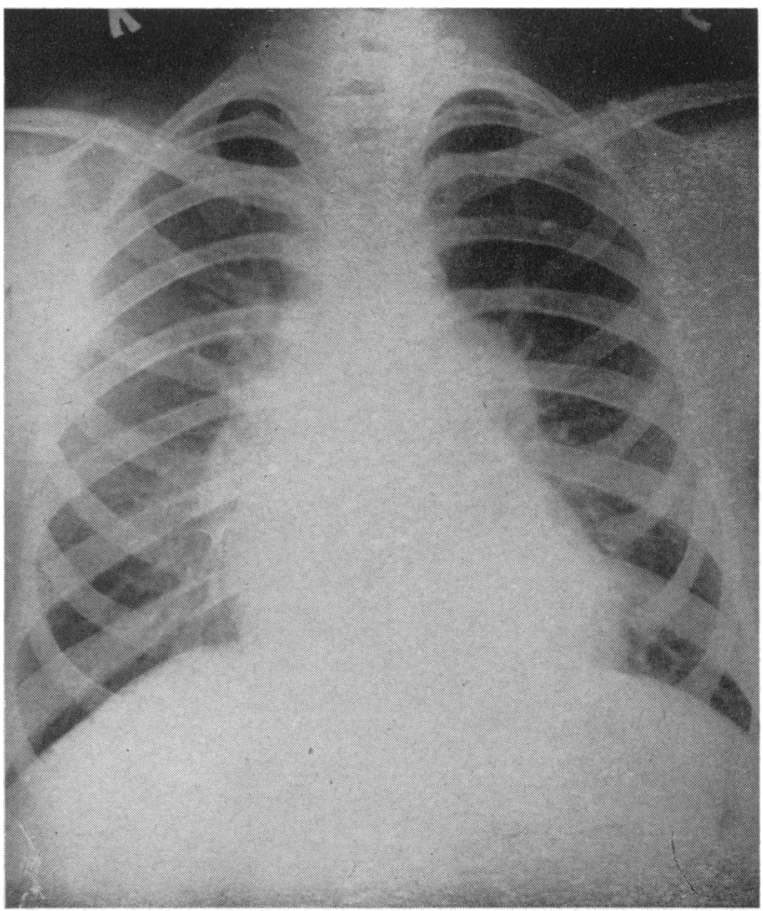

Fig. 10

FIG. 6.-Aortography with balloon catheter (left oblique view). Contrast material is seen in both aorta and pulmonary artery.

Fig. 7.-Aortography on another patient. This film, taken at 2 seconds, shows contrast material in lower-lobe pulmonary artery and aorta.

FIg. 8.-Same patient as Fig. 7, showing further filling of pulmonary artery at 4 seconds.

Fig. 9.-Chest radiograph taken before splenectomy.

Fig. 10.-Chest radiograph of same patient as Fig. 9 taken 18 months after splenectomy, showing reduction in heart size and smaller left pulmonary artery. 